\title{
Social Skills and Relationships in Turner Syndrome
}

\section{Abstract}

Purpose of review: Summarise the literature on the social skills and relationships of females with Turner Syndrome (TS) and examine the biological and psychological factors that may contribute to social interaction difficulties.

Recent Findings: Turner syndrome is often associated with impaired social-cognitive processing and executive function deficits. These cognitive abnormalities, together with a range of physical differences, may adversely affect social communication skills, which typically begin to impair quality of life during early adolescence. Parental accounts of their daughter's social skills frequently highlight interaction problems, both in the home and beyond; in contrast, self-reports are usually far more positive. At present, we do not know the extent to which such self-reports reflect a lack of social awareness, or a lack of concern about social difficulties.

Summary: Women with TS experience are likely to experience social interaction challenges (especially in friendships and relationships) across the lifespan. Providing appropriate guidance and support to them demands a better understanding of their strengths and weaknesses.

\section{Key words:}

Turner syndrome, social skills, sex chromosome aneuploidy, social cognition, relationships

\section{Key points:}

- TS is associated with a range of social-cognitive processing problems which co-exist with executive function deficits. These cognitive abnormalities, together with complex range of physical differences, may predispose to social interaction difficulties.

- Social interaction challenges typically begin adversely to affect quality of life during early adolescence and persist across the lifespan; they are often associated with social isolation. Romantic relationships are infrequent, relative to typical females, and they begin in later life than usual.

- Few qualitative studies of subjective social interaction experiences have been conducted. At present, we do not know the extent to which affected females (especially those in adolescence) are aware of their social differences and the extent to which they regard them as problematic.

\section{Authors:}

Wolstencroft, J \& Skuse, D.H.

\section{Corresponding author:}

Jeanne Wolstencroft

UCL GOS Institute of Child Health

30 Guilford Street

London

WC1N 1EH

02079052168

j.wolstencroft@ucl.ac.uk 


\section{Please confirm:}

This manuscript has been seen, reviewed, and approved by all contributing authors. YES

Are there any acknowledgements/ potential conflicts of interest/ Financial support and sponsorship to disclose? YES

\section{Financial support and sponsorship}

This work was supported by the Child Health Research CIO and BRC Infrastructure funding.

\section{Conflicts of interest}

The authors have no conflicts of interest. 


\section{Social Skills and Relationships in Turner Syndrome}

\section{Word count: 2284}

\section{Introduction}

Turner Syndrome (45,X; TS) is a common sex chromosome aneuploidy, affecting 1 in 2500 female births $^{1}$. TS is caused by the partial or complete loss of one $X$ chromosome in females. In approximately $70 \%$ of cases the chromosomal loss is caused by paternal non-disjunction ${ }^{2}$, and the intact $X$ is of maternal origin. The complete loss of one $X$ chromosome (monosomy) affects approximately $45 \%^{3}$. The other $55 \%$ have structural anomalies of one $X$ chromosome, usually associated with cellular mosaicisms $\mathrm{s}^{3,4}$.

TS is associated with a wide range of physical health concerns that require clinical monitoring across the lifespan, including short stature, impaired hearing, infertility, cardiac abnormalities, diabetes and disorders of thyroid function ${ }^{4}$ as well as challenges to psychological wellbeing. From early childhood, females with TS experience an excess of behavioural, emotional and social difficulties compared with typical females of the same age ${ }^{5}$. These include traits of anxiety and depression, low self-esteem and, in particular, less good social interaction skills ${ }^{6-13}$.

\section{Social skills}

'Social skills' are usually defined as the successful performance of age-appropriate behaviours in social contexts ${ }^{14-16}$. We need such skills to attain and to maintain good psychosocial adjustment; deficits in social skills have a significant negative impact on academic, adaptive and psychological functioning ${ }^{17-20}$. In order to support social skills effectively, and to design interventions that work, operationalising a formal measure of good social skills is necessary. Unfortunately, the construct remains poorly defined and for that reason, among others, it is difficult objectively to assess. Individuals who are lacking social skills are likely to suffer rejection, isolation and the inability to sustain intimate relationships. Planning a therapeutic intervention to ameliorate the secondary consequences of low social competence requires: first, some understanding of the origins of the social skill deficit; second, the ability to characterise objectively the specific deficits that have led to a failure of appropriate social integration.

Helpful distinctions to make when designing a therapeutic intervention include the following: first, whether the lack of social skills represents an acquisition deficit, in which age-appropriate skills have not been learned or acquired ${ }^{21}$; second, whether, insofar as there is no acquisition deficit, the affected individual suffers from a performance deficit. If there is a primary performance deficit, the affected individual is failing to perform previously learned social skills appropriately.

Social interaction challenges in TS have been reported since the first studies of psychological wellbeing and psycho-social function, over thirty years ago (Table 1). In childhood, this information is provided by parental report, from measures of social withdrawal and other social problems ${ }^{22}$. On the basis of such reports, social adjustment is found to be significantly worse in girls with TS, not only in comparison to typically developing females ${ }^{7,8,23,24}$, but also those with short stature ${ }^{8,25,26}$. Not all are affected; one in four does not have serious difficulties ${ }^{7}$.

Despite the magnitude of the chromosomal disorder, most females with TS have verbal intelligence within the normal range; their social difficulties do not derive from generalized intellectual disability. Social knowledge appears to be acquired normally until social demands exceed their capacity to perform at an age-appropriate level. Many affected females consciously attempt to compensate for their social performance deficits ${ }^{11}$. Peer relationships are not usually a concern to friends or 
teachers during early and middle childhood (7-13 years) ${ }^{7}$. The most significant social difficulties with the peer group emerge, and become more impairing during adolescence. During mid-adolescence many TS girls lose confidence, and that can be exacerbated by adverse peer reactions, leading to their becoming socially withdrawn ${ }^{5}$. For many girls, this is a coping strategy ${ }^{27}$.

Indicators of social competence in TS have typically been provided by report (usually from parental enquiry). The quality of social interactions has rarely been examined by means of behavioural observations. In order to map out more precisely the characteristics of TS-related social behaviour through the lifespan, observational studies would be of potential value. Novel socio-metric techniques that map social-group networks could be employed to identify the developmental course taken by affected girls of school-age ${ }^{28}$.

Self-reports of social competence have proved to be difficult to interpret; the results often appear contradictory. For example, young women with TS score similarly to their sisters on a self-reported social skills questionnaire. Yet they recount experiencing more social difficulties than their sisters in qualitative interviews ${ }^{29}$. In general, self-reports from girls with TS do not match parental descriptions either. We suggest these discrepancies shed light on the nature of the social deficit. Young women with TS are able correctly to identify appropriate social behaviours in order to obtain good scores on a questionnaire ${ }^{29}$, which indicates they have acquired good social knowledge. This tendency to minimise their social difficulties when self-reporting, gives a mistaken impression of real-world competence ${ }^{30}$. Other young people with poor social competence (such as girls with autism spectrum disorders (ASD)), also report 'desirable' as opposed to their 'actual' social performance ${ }^{31}$.

These findings indicate there could be a social desirability response bias, but objective evidence is lacking. Currently, we do not know whether the inaccurate self-reports imply that girls with TS have poor self-insight into their own social abilities or whether they reflect an inappropriate degree of social satisfaction ${ }^{29}$. To date, there is little qualitative research, so we need to explore more closely the social experiences of women with TS and how these change over time. Successful compensatory strategies could be incorporated into educational programmes to assist those with persistent and troubling difficulties.

[TABLE 1] 


\section{Friendships and Relationships}

When asked about their social relationships in adulthood, most (70\%) women with TS say they had a best friend in childhood. A similar proportion (78\%) claim to have a close friend other than a family member in adulthood ${ }^{32}$. Nevertheless, more adults with TS feel socially isolated than population norms $s^{32,33}$.

Women with TS are less likely to have a partner in adulthood than typical females of similar age. Those who have formed stable relationships did so at a later age than average ${ }^{34-36} .{ }^{37}$ They are less likely than typical adults to be married ${ }^{34,36,38,39}$ although that proportion varies substantially by country of birth (Scandinavia 16\%, Poland 25\%, USA 32\%) ${ }^{32,40,41}$. There is little information available about the long-term stability of marital relationships, but one study of young TS women found $15 \%$ were divorced ${ }^{41}$.

In general, the first sexual relationship occurs later than average (based on the relevant social norms) and there is less sexual activity than typical females of similar age ${ }^{35-38}$. Objective evidence exists of sexual dysfunction, related in part to hormonal anomalies that are an inherent aspect of the syndrome. On the other hand, women with TS are usually satisfied with their sex lives and with their intimate relationships ${ }^{37}$. Infertility may have an impact on how women with TS interact with their partners. Some women fear rejection after disclosing details of their condition ${ }^{41}$. There is little known about sexual orientation in TS, although there is some evidence that it is usually heteronormative ${ }^{42}$. However, in view of recent societal changes in sexual attitudes ${ }^{43}$, this issue merits reexamination.

\section{Biological correlates of social skills difficulties}

Early psychological research on wellbeing focused on how the somatic characteristics of the syndrome affected self-image and how others perceived TS. There was a widespread view that the associated short stature, and failure to develop secondary sexual characteristics, were largely responsible for the impact of the syndrome on social adjustment and social skills ${ }^{7}$. Consequently, hormone therapy (GH and oestrogen) was prescribed with a view to improving self-esteem and quality of life. Short stature is nowadays recognised as just one issue contributing to social adjustment difficulties, many of which are due to fundamental impairments in social cognition ${ }^{44}$.

\section{Physical differences}

Girls with TS do not usually go into spontaneous puberty, because of the associated estrogen deficiency. The current approach to endocrinological therapy aims to maximise final stature, but also to induce an age-appropriate onset of puberty. Both delayed puberty (with the risk of associated risk of teasing, and social rejection) and excessive short stature have been linked to later social interaction difficulties ${ }^{30,41}$, so to manage hormone replacement optimally requires delicate clinical judgement.

In later life, premature sensorineural hearing loss, which affects a large minority of women with TS, contributes to impaired social function ${ }^{45-47}$. Recurrent otitis media in childhood, which affects up to $60 \%$, can also lead to hearing loss due to chronic cochlear damage. Regular hearing checks are indicated in this condition, starting in childhood and continuing throughout the lifespan. 


\section{Cognitive differences}

Most females with TS do not have impaired intellectual abilities, but there is an imbalance in their verbal and non-verbal domain skills. Verbal intelligence is usually within the normal range, but visuospatial and visuo-motor skills are about half a standard deviation lower ${ }^{6,48}$. Poor executive function skills are common, and are associated with impaired attention, working memory, cognitive flexibility, processing speed and abstract reasoning ${ }^{49-51}$.

Social cognition in TS is affected, leading to poor face recognition, emotion recognition, direction of eye gaze and theory of mind ${ }^{45,51-53}$. There are associated configural processing difficulties ${ }^{54-56}$. Facial

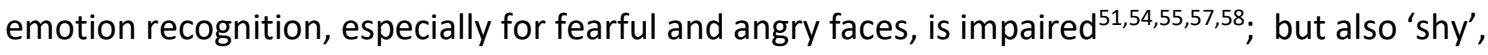
'hostile' and 'anxious' ${ }^{59}$. When asked to focus their attention on facial features, eye-tracking experiments show that affected females tend to look at mainly at the mouth, and so fail to pick up cues given by the eye regions during these tasks ${ }^{54}$.

These differences in emotion recognition cannot be explained adequately by the associated deficits in visuo-spatial processing, global face recognition, performance IQ or karyotype ${ }^{45,55,60}$. They reflect fundamental problems in the processing of social perceptions that are due to the genomic consequences of $\mathrm{X}$-monosomy ${ }^{13}$.

When asked to determine subtle distinctions in the direction in which someone else is looking, adult women with TS are less accurate than controls ${ }^{61}$, possibly because they pay insufficient attention to the eye region. Difficulties are also found in their ability to infer other people's feelings and intentions from their non-verbal behaviour; this deficit in 'theory of mind' can be observed in the 'Mind in the Eyes' task ${ }^{62}$.

The lack of oestrogen and growth hormone in early life could contribute to impaired socio-cognitive skills in later life, possibly because it occurred during a critical period of brain development. Hormone replacement therapy in later childhood fails to improve psycho-social performance or cognitive function but may have come too late to rectify it $27,45,53,63,64$.

Many features of the socio-cognitive profile of TS are reminiscent of difficulties experienced by people with an ASD. TS is associated with an increased risk of traits similar to those observed in females with high-functioning idiopathic autistic disorders ${ }^{4}$. Few studies investigating psychopathology have included standardized assessments of neurodevelopmental functioning, hence the clinical significance of these traits is not known for sure. Many young women with TS score retain high levels of social motivation, despite marked autistic characteristics in other respects $^{60,62}$.

\section{Genetics}

There is no evidence that specific TS-related chromosomal variants (e.g. structural variants, degree of mosaicism, monosomy) are associated with better or worse psycho-social dysfunction ${ }^{65}$, unless there is associated severe intellectual disability, which is rare with the exception of ring chromosomes ${ }^{66}$.

Most women with TS inherit their single intact X-chromosome from their mother. A controversial theory proposes the impact of genomic imprinting on key X-linked genes, which would silence some critical genes on the maternally derived X-chromosome in normal males and females. According to this theory, the paternal X-chromosome possesses equivalent genes that are not imprinted (i.e. are 
not silenced) and those genes have functions that protect females from expressing autistic traits. Remember that normally a paternally-derived X-chromosome is always passed only to daughters. As normal males invariably inherit their single $X$ from their mothers, they inherit the silenced imprinted genes. Therefore, they are more predisposed than typical females (who possess $\mathrm{X}$-chromosomes from both parents) to manifest an autistic phenotype, if subject to other (polygenic) risk factors.

The theory predicts that monosomic TS women who have inherited a single X from their father will in general be less socially impaired than those monosomic TS women who have inherited their single intact $X$ chromosome from their mother ${ }^{9}$. This theory was supported by behavioural evidence when first published in the 1990s but attempts to replicate the initial findings have not been successful to date. Furthermore, the genetic mechanism involved has not yet been identified.

\section{Intervention}

Only a handful of psychological interventions to improve cognitive functioning in TS have been attempted ${ }^{67-69}$, and few have focused explicitly on enhancing social skills. Interventions have not used evidence-based programmes, nor been manualised. No randomised controlled trials have been conducted. These deficiencies must be rectified, and treatment programmes used to remedy social skills in ASD have been recommended. The latest TS treatment guidelines ${ }^{4}$ explicitly mention the need to pilot PEERS ${ }^{70}$, which is a group-based social skills training programme for adolescents and young adults with ASD. The success of such programmes will depend upon a better understanding of the degree to which TS females have good social knowledge, and the precise causes of their deficits in social performance in terms of individual cognitive strengths and weaknesses.

\section{Conclusions}

TS is associated with a range of social-cognitive processing problems which co-exist with executive function deficits and a complex range of physical differences, which may predispose them to social interaction difficulties. Disentangling the contributions of mental, physical and environmentally engendered processes to social adjustment will be critical in order to formulate better-targeted interventions. It is encouraging to find that social motivation is preserved in TS, but we do not know the extent to which those affected are aware of their social differences and the extent to which they regard them as problematic. Future research will need to take a more holistic approach in order to fully understand the social challenges experienced by affected females.

\section{Reference annotations:}

\section{** 4. Gravholt et al.}

The clinical care guidelines for TS provide a comprehensive medical overview of the syndrome and highlights recent advances in treatment.

\section{** 29. Suzigan}

Using structured questionnaires and qualitative interviews with multiple informants, this study shows that young women with TS have good social knowledge. The researchers also address social self-insight, suggesting either that young women with TS may not be aware of their social difficulties, or that these difficulties are not perceived as problematic.

\section{* 62. Hong et al.}


Comprehensive study of social cognition in young girls with TS showing that social difficulties are present from an early age (before hormone replacement therapy) and that social motivation is preserved.

\section{REFERENCES}

1. Jacobs, P. et al. Turner syndrome: a cytogenetic and molecular study. Ann. Hum. Genet. 61, 471-483 (1997).

2. Mathur, A. et al. The parental origin of the single $X$ chromosome in Turner syndrome: lack of correlation with parental age or clinical phenotype. Am. J. Hum. Genet. 48, 682 (1991).

3. Wolff, D. J., Van Dyke, D. L. \& Powell, C. M. Laboratory guideline for Turner syndrome. Genet. Med. 12, 52-55 (2010).

4. Gravholt, C. H. et al. Clinical practice guidelines for the care of girls and women with Turner syndrome: proceedings from the 2016 Cincinnati International Turner Syndrome Meeting. Eur. J. Endocrinol. 177, 1-70 (2017).

5. Boman, U. W., Möllet, A. \& Albertsson-Wikland, K. Psychological aspects of Turner syndrome. J. Psychosom. Obstet. Gynecol. 19, 1-1 (1998).

6. McCauley, E., Kay, T., Ito, J. \& Treder, R. The Turner syndrome: cognitive deficits, affective discrimination, and behavior problems. Child Dev. 58, 464-73 (1987).

7. Rovet, J. \& Ireland, L. Behavioral Phenotype in Children with Turner Syndrome. J. Pediatr. Psychol. 19, 779-790 (1994).

8. McCauley, E., Ross, J. L., Kushner, H. \& Cutler, G. Self-esteem and behavior in girls with Turner syndrome. J. Dev. Behav. Pediatr. 16, 82-8 (1995).

9. Skuse, D. H. et al. Evidence from Turner's syndrome of an imprinted X-linked locus affecting cognitive function. Nature 387, 705-708 (1997).

10. Skuse, D. The psychological consequences of being small. J. Child Psychol. Psychiatry 28, 641650 (1987).

11. Mccauley, E., Feuillan, P., Kushner, H., Ross, J. L. \& University, T. J. Psychosocial development in adolescents with Turner syndrome. J. Dev. Behav. Pediatr. 22, 360-365 (2001).

12. Lagrou, K. et al. Psychosocial functioning, self-perception and body image and their auxologic correlates in growth hormone and oestrogen-treated young adult women with Turner syndrome. Horm. Res. Paediatr. 66, 277-284 (2006).

13. Skuse, D., Elgar, K. \& Morris, E. Quality of life in Turner syndrome is related to chromosomal constitution: implications for genetic counselling and management. Acta Paediatr. 88, 110113 (1999).

14. Rubin, K. H. \& Rose-Krasnor, L. Interpersonal problem solving and social competence in children. in Handbook of social development 283-323 (Springer, 1992).

15. Nangle, D. W., Grover, R. L., Holleb, L. J., Cassano, M. \& Fales, J. Defining competence and identifying target skills. in Practitioner's Guide to Empirically Based Measures of Social Skills 3-19 (Springer, 2010).

16. McFall, R. M. A review and reformulation of the concept of social skills. Behav. Assess. (1982).

17. Elliott, S. N., Malecki, C. K. \& Demaray, M. K. New Directions in Social Skills Assessment and 
Intervention for Elementary and Middle School Students. Exceptionality 9, 19-32 (2001).

18. Roff, M., Sells, S. B. \& Golden, M. Social Adjustment and Personality Development in Children. (University of Minnesota Press, 1972).

19. Spence, S. H. Social Skills Training with Children and Young People: Theory, Evidence and Practice. Child Adolesc. Ment. Health 8, 84-96 (2003).

20. Coie, J., Terry, R., Lenox, K., Lochman, J. \& Hyman, C. Childhood peer rejection and aggression as predictors of stable patterns of adolescent disorder. Dev. Psychopathol. 7, 697 (1995).

21. Gresham, F. M. Social competence and students with behavior disorders: Where we've been, where we are, and where we should go. Educ. Treat. Child. 233-249 (1997).

22. Achenbach, T. Integrative guide for the $1991 \mathrm{CBCL} / 4-18, \mathrm{YSR}$, and TRF profiles. Burlington: University of Vermont, Department of Psychiatry (1991).

23. Swillen, A. et al. Intelligence, behaviour and psychosocial development in Turner syndrome. A cross-sectional study of 50 pre-adolescent and adolescent girls (4-20 years). Genet. Couns. 4, 7-18 (1993).

24. Rovet, J. F. The Psychoeducational Characteristics of Children with Turner Syndrome. J. Learn. Disabil. 26, 333-341 (1993).

25. McCauley, E., Ito, J. \& Kay, T. Psychosocial Functioning in Girls with Turner's Syndrome and Short Stature: Social Skills, Behavior Problems, and Self-Concept. J. Am. Acad. Child Psychiatry 25, 105-112 (1986).

26. Skuse, D., Percy, E. \& Stevensen, J. Psychosocial functioning in the Turner syndrome: A national survey. in Growth, stature and adaptation (eds. Stabler, B. \& Underwood, L.) 151164 (Chapel Hill, NC, 1994).

27. Lesniak-Karpiak, K., Mazzocco, M. M. M. \& Ross, J. L. Behavioral Assessment of Social Anxiety in Females with Turner or Fragile X Syndrome. J. Autism Dev. Disord. 33, 55-67 (2003).

28. Kasari, C., Locke, J., Gulsrud, A. \& Rotheram-Fuller, E. Social networks and friendships at school: Comparing children with and without ASD. J. Autism Dev. Disord. (2011).

doi:10.1007/s10803-010-1076-x

29. Suzigan, L. Z., De Paiva e Silva, R. B., Guerra-Junior, G., Marini, S. H. V. L. \& Maciel-Guerra, A. T. Social skills in women with Turner Syndrome. Scand. J. Psychol. 52, 440-447 (2011).

30. Lagrou, K. et al. Age-Related Perception of Stature, Acceptance of Therapy, and Psychosocial Functioning in Human Growth Hormone-Treated Girls with Turner's Syndrome. J. Clin. Endocrinol. Metab. 83, 1494-1501 (1998).

31. Bauminger, N. \& Kasari, C. Loneliness and Friendship in High-Functioning Children with Autism. Child Development 71, 447-456 (2000).

32. Boman, U. W., Bryman, I., Halling, K. \& Möller, A. Women with Turner syndrome: psychological well-being, self-rated health and social life. J. Psychosom. Obstet. Gynaecol. 22, 113-22 (2001).

33. Amundson, E., Boman, U. W., Barrenäs, M.-L., Bryman, I. \& Landin-Wilhelmsen, K. Impact of Growth Hormone Therapy on Quality of Life in Adults with Turner Syndrome. J. Clin. Endocrinol. Metab. 95, 1355-1359 (2010).

34. Aran, O. et al. Social, educational and vocational status of 48 young adult females with 
gonadal dysgenesis. Clin. Endocrinol. (Oxf). 36, 405-410 (1992).

35. Pavlidis, K., McCauley, E. \& Sybert, V. P. Psychosocial and sexual functioning in women with Turner syndrome. Clin. Genet. 47, 85-89 (1995).

36. Nielsen, J., Nyborg, H. \& Dahl, G. A psychiatric and psychological study of 45 women with Turner syndrome, compared with their sisters and women with normal karyotypes, growth retardation and primary amenorrhea. Acta Jutl. Medicine S, (1977).

37. Rolstad, S. G., Möller, A., Bryman, I. \& Boman, U. W. Sexual functioning and partner relationships in women with turner syndrome: Some empirical data and theoretical considerations regarding sexual desire. J. Sex Marital Ther. 33, 231-247 (2007).

38. Downey, Ehrhardt, Gruen, Bell \& Morishima. Psychopathology and Social Functioning in Women with Turner Syndrome. J. Nerv. Ment. Dis. 177, 191-201 (1989).

39. Holl, R. W., Kunze, D., Etzrodt, H., Teller, W. \& Heinze, E. Turner syndrome: final height, glucose tolerance, bone density and psychosocial status in 25 adult patients. Eur J Pediatr 153, 11-16 (1994).

40. Jeż, W. et al. Social and medical determinants of quality of life and life satisfaction in women with Turner syndrome. Adv. Clin. Exp. Med. 27, 229-236 (2018).

41. Sutton, E. J. et al. Turner syndrome: four challenges across the lifespan. Am. J. Med. Genet. A 139A, 57-66 (2005).

42. Hettmer, E., Hoepffner, W., Keller, E. \& Brähler, E. Studies on sexual development, sexual behavior and ability to experience sex of young women with Ullrich-Turner syndrome. Ther. Umsch. 52, 146-9 (1995).

43. Mercer, C. H. et al. Changes in sexual attitudes and lifestyles in Britain through the life course and over time: findings from the National Surveys of Sexual Attitudes and Lifestyles (Natsal). Lancet (London, England) 382, 1781-94 (2013).

44. Hong, D. S. \& Reiss, A. L. Cognition and behavior in Turner syndrome: a brief review. Pediatr. Endocrinol. Rev. 9 Suppl 2, 710-2 (2012).

45. Hong, D. S., Kent, J. S. \& Kesler, S. Cognitive profile of Turner syndrome. Dev. Disabil. Res. Rev. 15, 270-278 (2009).

46. Hultcrantz, M. \& Sylvén, L. Turner's syndrome and hearing disorders in women aged 16-34. Hear. Res. 103, 69-74 (1997).

47. Bergamaschi, R. et al. Hearign loss in Turner Syndrome: Results of a multicentric study. J. Endocrinol. Invest. 31, 779-783 (2008).

48. Nijhuis-van der Sanden, M. W. G. G., Eling, P. A. T. M. T. M. \& Otten, B. J. A review of neuropsychological and motor studies in Turner Syndrome. Neurosci. Biobehav. Rev. 27, 329338 (2003).

49. Buchanan, L., Pavlovic, J. \& Rovet, J. A reexamination of the visuospatial deficit in turner syndrome: Contributions of working memory. Dev. Neuropsychol. 14, 341-367 (1998).

50. Lepage, J.-F., Dunkin, B., Hong, D. S. \& Reiss, A. L. Contribution of Executive Functions to Visuospatial Difficulties in Prepubertal Girls With Turner Syndrome. Dev. Neuropsychol. 36, 988-1002 (2011).

51. Romans, S. M., Stefanatos, G., Roeltgen, D. P., Kushner, H. \& Ross, J. L. Transition to young 
adulthood in Ullrich-Turner syndrome: Neurodevelopmental changes. Am. J. Med. Genet. 79, 140-147 (1998).

52. Reiss, A. L. et al. The effects of $X$ monosomy on brain development: Monozygotic twins discorcant for Turner's syndrome. Ann. Neurol. 34, 95-107 (1993).

53. Ross, J. L., Feuillan, P., Kushner, H., Roeltgen, D. \& Cutler, G. B. Absence of Growth Hormone Effects on Cognitive Function in Girls with Turner Syndrome. J. Clin. Endocrinol. Metab. 82, 1814-1817 (1997).

54. Mazzola, F. et al. Eye tracking and fear recognition deficits in Turner syndrome. Soc. Neurosci. 1, 259-269 (2006).

55. Lawrence, K., Kuntsi, J., Coleman, M., Campbell, R. \& Skuse, D. Face and emotion recognition deficits in Turner syndrome: a possible role for X-linked genes in amygdala development. Neuropsychology 17, 39 (2003).

56. Anaki, D., Zadikov Mor, T., Gepstein, V. \& Hochberg, Z. Face perception in women with Turner syndrome and its underlying factors. Neuropsychologia 90, 274-285 (2016).

57. Good, C. D. et al. Dosage-sensitive X-linked locus influences the development of amygdala and orbitofrontal cortex, and fear recognition in humans. Brain 126, 2431-2446 (2003).

58. Morel, A. et al. Overview of Social Cognitive Dysfunctions in Rare Developmental Syndromes With Psychiatric Phenotype. Front. Pediatr. 6, 102 (2018).

59. Lawrence, K. et al. Interpreting gaze in Turner syndrome: impaired sensitivity to intention and emotion, but preservation of social cueing. Neuropsychologia 41, 894-905 (2003).

60. Lepage, J.-F., Dunkin, B., Hong, D. S. \& Reiss, A. L. Impact of cognitive profile on social functioning in prepubescent females with Turner syndrome. Child Neuropsychol. 19, 161-172 (2013).

61. Elgar, K., Campbell, R. \& Skuse, D. Are you looking at me? Accuracy in processing line-of-sight in Turner syndrome. Proc. R. Soc. London B Biol. Sci. 269, 2415-2422 (2002).

62. Hong, D. S., Dunkin, B. \& Reiss, A. L. Psychosocial functioning and social cognitive processing in girls with Turner syndrome. J. Dev. Behav. Pediatr. JDBP 32, 512-20 (2011).

63. Ross, J. L. et al. Persistent cognitive deficits in adult women with Turner syndrome. Neurology 58, 218-25 (2002).

64. Ross, J. L. et al. The Effect of Genetic Differences and Ovarian Failure: Intact Cognitive Function in Adult Women with Premature Ovarian Failure Versus Turner Syndrome. J. Clin. Endocrinol. Metab. 89, 1817-1822 (2004).

65. Kesler, S. R. Turner Syndrome. Child Adolesc. Psychiatr. Clin. N. Am. 16, 709-722 (2007).

66. Kuntsi, J., Skuse, D., Elgar, K., Morris, E. \& Turner, C. Ring-X chromosomes: their cognitive and behavioural phenotype. Ann. Hum. Genet. 64, 295-305 (2000).

67. Hynes, P. \& Phillips, W. Turner's Syndrome: Assessment and Treatment for Adult Psychiatric Patients. Am. J. Psychother. 38, 558-565 (1984).

68. Watson, M. A. \& Money, J. Behavior Cytogenetics and Turner's Syndrome: A New Principle in Counseling and Psychotherapy. Am. J. Psychother. 29, 166-178 (1975).

69. Chadwick, P. M., Smyth, A. \& Liao, L.-M. Improving self-esteem in women diagnosed with Turner syndrome: results of a pilot intervention. J. Pediatr. Adolesc. Gynecol. 27, 129-32 
(2014).

70. Laugeson, E. A. \& Frankel, F. Social skills for teenagers with developmental and autism spectrum disorders: The PEERS treatment manual. (Routledge, 2011). 